\title{
Genetic polymorphism of merozoite surface protein-1 and merozoite surface protein-2 in Plasmodium falciparum isolates from children in South of Benin
}

\author{
Aurore Ogouyèmi-Hounto ${ }^{1,3, *}$, Dorothée Kinde Gazard ${ }^{1,3}$, Nicaise Ndam ${ }^{2,3}$, Elsa Topanou ${ }^{3}$, \\ Olivia Garba ${ }^{3}$, Pancras Elegbe ${ }^{3}$, Tatiana Hountohotegbe ${ }^{3}$, and Achille Massougbodji ${ }^{1}$ \\ ${ }^{1}$ Unité d'Enseignement et de Recherche en Parasitologie-Mycologie de la Faculté des Sciences de la Santé, 01BP188 Cotonou, Bénin \\ 2 Institut de Recherche pour le Développement, 08BP841 Cotonou, Bénin \\ 3 Laboratoire du Centre de Lutte Intégrée contre le Paludisme, 01BP188 Cotonou, Bénin
}

Received 17 July 2013, Accepted 6 October 2013, Published online 21 October 2013

\begin{abstract}
The aim of this study was to determine the genetic diversity of Plasmodium falciparum by analyzing the polymorphism of the $m s p-1$ and $m s p-2$ genes and the multiplicity of infection in children with uncomplicated malaria in southern Benin. Blood samples of children with fever or history of fever with thick smear positive P. falciparum were collected on filter paper. After extraction of DNA by Chelex ${ }^{\circledR}$, the samples underwent nested PCR. 93 isolates from children were genotyped. For the $m s p-1$ gene, the K1 and R033 sequences were the most represented in the study population with $85.2 \%$ and $83 \%$ prevalence, respectively. Regarding the $m s p-2$ gene, the FC27 family was more highly represented with $99 \%$ prevalence against $81.5 \%$ for 3D7. Mixed infections accounted for $80.4 \%$ of the samples. Twenty-five alleles were identified for $m s p-1$ and 28 for $m s p-2$. Fourteen and ten alleles belonged to the K1 (100$500 \mathrm{bp}$ ) and MAD20 (100-500 bp) families, respectively. The RO33 sequence did not show any polymorphism, with only one variant (160 bp) detected. The $m s p-2$ gene was present as 16 FC27 family fragments (250-800 bp) and 12 of the 3D7 family (350-700 bp). The multiplicity of infection was estimated at 3.8 for $m s p-1$ and 3.9 for $m s p-2$ with 77 $(87.5 \%)$ and $84(91.3 \%)$ samples harboring more than one parasite genotype for $m s p-1$ and $m s p-2$, respectively. The multiplicity of infection (MOI) was influenced neither by age nor by parasite density. This study shows a significant diversity of $P$. falciparum in southern Benin with an MOI unaffected by age or by parasite density.
\end{abstract}

Key words: Benin, Genotyping, Merozoite surface protein, Plasmodium falciparum.

Résumé - Polymorphisme génétique de la protéine de surface du mérozoïte 1 et de la protéine de surface du mérozoïte 2 dans des isolats de Plasmodium falciparum d'enfants du Sud du Bénin. Le but de cette étude était de déterminer la diversité génétique de Plasmodium falciparum en analysant le polymorphisme des gènes $m s p-1$ et $m s p-2$ et la multiplicité de l'infection chez les enfants souffrant de paludisme simple au sud du Bénin. Les enfants présentant une fièvre ou antécédents de fièvre avec une goutte épaisse positive à $P$. falciparum ont subi un prélèvement de sang sur papier buvard. Après extraction de l'ADN au Chelex ${ }^{\circledR}$, les échantillons ont fait l'objet d'une PCR nichée. Les isolats de 93 enfants ont été génotypés. Pour le gène $m s p-1$, les familles K1 et R033 étaient les plus représentées dans la population d'étude avec respectivement $85,2 \%$ et $82,9 \%$. Pour $m s p-2$, la famille FC27 était la plus représentée avec $98,9 \%$ contre $81,6 \%$ pour 3D7. Les infections mixtes représentaient $80,4 \%$ des échantillons. Vingt-cinq allèles ont été identifiés pour $m s p-1$ et 28 pour $m s p$-2. Quatorze et dix allèles appartenaient respectivement à la famille K1 (100-500 bp) et MAD20 (100-500 bp). Aucun polymorphisme n'a été noté avec la famille RO33, avec un seul fragment (160 bp) détecté. Le gène $m s p-2$ présentait 16 fragments pour FC27 (250-800 bp) et 12 pour 3D7 (350-700 bp). La multiplicité de l'infection était de 3,8 pour $m s p-1$ et 3,9 pour $m s p-2$ avec $77(87,5 \%)$ et 84 $(91,3 \%)$ échantillons qui avaient plus d'un génotype parasitaire respectivement pour $m s p-1$ et $m s p-2$. La multiplicité de l'infection (MOI) ne variait pas significativement avec l'âge ni avec la densité parasitaire. Cette étude montre une importante diversité de P. falciparum au sud du Bénin avec une MOI qui n'est influencée ni par l'âge ni par la densité parasitaire.

\footnotetext{
*Corresponding author: aurorefel@yahoo.fr
} 


\section{Introduction}

In Benin, $P$ falciparum infection is among the first diseases and is also responsible for $36 \%$ of deaths among children under 5 years (unpublished data from Ministry of Health). Despite the enormous efforts that have been directed toward malaria control and prevention, multiple factors including insecticide resistance in the anopheline vectors, and the emergence and rapid spread of drug-resistant parasite strains are major problems for the control and prevention of malaria. Therefore, the development of an effective malaria vaccine is urgently needed. One of the limitations to the development of this vaccine against $P$. falciparum is the extensive genetic diversity in parasite populations limiting the efficacy of acquired protective immunity to malaria [6]. Indeed, antigenic diversity is one of the hypotheses advanced to explain the slow acquisition of immunity against malaria in individuals living in malaria-endemic areas [15]. Asexual blood stage antigens, such as merozoite surface protein-1 (msp-1) and merozoite surface protein-2 (msp-2), are considered prime candidates for the development of a malaria vaccine and are also suitable markers for the identification of genetically distinct $P$. falciparum parasite sub-populations [5]. In Benin a study performed by Issifou et al. [9] noted a high prevalence of multiple infections influenced neither by age nor by season in a group of children and adults with uncomplicated malaria. Since then, no other study has explored the genetic diversity of $P$. falciparum malaria in Benin. Following scale up of malaria control interventions (massive deployment of insecticide-treated nets and free treatment with ACT) in the country, it is important to reassess genetic diversity of $P$. falciparum in Benin to better direct control actions. This study aimed to characterize the allelic polymorphism of $m s p-1$ and $m s p-2$ and determined the multiplicity of infection in $P$. falciparum isolates collected from children with uncomplicated malaria living in the southern Benin.

\section{Patients and methods}

\section{Study sites and population}

The study was conducted in two highly endemic regions of southern Benin, including the departments of Littoral and Ouémé. Southern Benin is characterized by a sub-equatorial climate and a perennial malaria transmission with two peaks corresponding to the rainy seasons (April-July and midSeptember-November) [20]. Children aged 6 months to 15 years who resided in the study sites for more than a period of 6 months were enrolled from May through August 2011. Children visiting the health facilities in the study area and who met the criteria below were enrolled in the study: (i) fever (axillary temperature $\geq 37.5^{\circ} \mathrm{C}$ ) or a history of fever within the past $48 \mathrm{~h}$; (ii) $P$. falciparum mono-infection with parasite density $\geq 1000$ asexual forms per microliter, identified by microscopy on blood smears; (iii) no evidence of a concomitant febrile illness; (iv) no sign/symptoms of severe malaria as defined by WHO [28]; and (v) written informed consent from parents.

\section{Sample collection and laboratory procedures}

Venous blood from symptomatic children fulfilling the above criteria was collected systematically on the filter paper. Thick and thin blood smears were prepared and were stained with $10 \%$ Giemsa for rapid diagnosis. All thick blood smears were examined against 500 leukocytes. Parasite densities were recorded as the number of parasites $/ \mu \mathrm{L}$ of blood, assuming an average leukocyte count of $8000 / \mu \mathrm{L}$ of blood. All slides were read in the health center's laboratory with external quality control performed on $10 \%$ of the negative slides and all positives in the Reference Laboratory of Parasitology of the Centre National Hospitalo Universitaire of Cotonou. Parasite DNA was extracted from filter papers using the Chelex 100 resin methods [19] and stored at $-20^{\circ} \mathrm{C}$ until use.

\section{Molecular genotyping of the polymorphic genes msp-1 and msp-2}

Specific primer pairs were used to amplify block 2 of $m s p-1$ and block 3 of $m s p-2[16,23]$. The two genes were amplified by nested PCR, each amplification with conserved or family specific primer pairs, being done separately, as described previously [25]. Analyses of the K1, MAD20, and RO33 allelic families of $m s p-1$ and the $3 D 7$ and FC27 allelic families of $m s p-2$ were performed sequentially in accordance with the genotyping protocol of Snounou et al. [25]. Allele-specific positive controls and DNA free negative controls were included in each set of reactions. Gel photographs were re-scored by visual comparison of DNA fragments and for individual samples, alleles were identified according to band size and the corresponding allelespecific primers used. The size of the PCR products was estimated using a 100 bp DNA ladder marker (Boehringer Mannheim, Marker VI).

\section{Data analysis}

The data were entered in the software $\mathrm{R}$ version 2.12.0 ( $\mathrm{R}$ Foundation for Statistical Computing, Vienna, Austria). The distribution of allelic families of $m s p-1$ and $m s p-2$ genes was determined by the number of PCR products corresponding to each family within the total number of samples. The number of patients with more than one amplified PCR fragment within the total population is defined as the frequency of polyclonal infections. The multiplicity of infection (MOI) was calculated as the total number of detected Plasmodium falciparum $m s p-1, m s p-2$ genotypes/total number of infected children [12]. Student's test was used to compare MOI. The chi-square test or Fisher's exact test was used for proportion comparisons. The $p$ value $<0.05$ was chosen as threshold significance for the various statistical tests.

\section{Ethics statement}

The Ethical Committee of the School of Medicine and Health Sciences, University of Benin, gave the ethical approval for the study. Written informed consent from head of school and parents was received. 
Table 1. Demographic and parasitological data of the study population.

\begin{tabular}{lc}
\hline Characteristics of patients & Values \\
\hline Mean age (year) & $7.9 \pm 0.4$ \\
Age range & 6 months to 15 years \\
Sex ratio $(\mathrm{M} / \mathrm{F})$ & $1.3(53 / 40)$ \\
Geometric mean of parasitemia & $19,093[12,698 ; 28,707]$ \\
Parasite density range $(\mathrm{p} / \mu \mathrm{L})$ & $1,000-160,000$ \\
\hline
\end{tabular}

\section{Results}

\section{Demographic and parasitological data of the study population}

Over a period of 4 months, 93 children meeting the inclusion criteria were recruited to the study. The characteristics of the study population are detailed in Table 1. The children's ages ranged from 6 months to 15 years (mean age: $7.9 \pm 0.4$ years). The parasite density ranged from 1,000 to 160,000 parasites/ $\mu \mathrm{L}$ with a mean density of 19,093 .

The parasite DNA from the $93 P$. falciparum isolates was analyzed for $m s p-1$ and $m s p-2$ genes. The efficiency of $m s p-1$ and $m s p$-2 gene amplification reactions with family-specific primers was $94.6 \%(88 / 93)$ and $99 \%$ (92/93), respectively.

\section{Genetic diversity of $P$. falciparum $m s p-1$ and $m s p-2$ gene}

The distribution of the different allelic families of $m s p-1$ and $m s p-2$ genes is shown in Table 2 . The K1 family was the predominant allelic type among mixed infections with RO33 $(20.5 \%)$ and most represented in the overall population (85.2\% prevalence) following by the RO33 sequence (83\%) without significant difference $p>0.05$. For the $m s p-2$ gene, the FC27 family was more represented but the difference was not statistically significant $(p=0.57)$.

The number of $m s p-1$ and $m s p-2$ genotypes per isolate ranged from 1 to 9 . The MOI was $3.8 \pm 0.35$ for $m s p-1$ and $3.9 \pm 0.30$ for $m s p-2$. Multiple infections were found in $87.5 \%$ (77/88) of samples for $m s p-1$ and $91.3 \%$ (84/93) of samples for $m s p-2$. Overall ( $m s p-1+m s p-2)$, the multiplicity of infection was 4 PCR fragments per individual infected, with $72(81.8 \%)$ of the samples harboring more than one parasite genotype.

According to age, and parasite density the MOI was similar between individuals of different age and parasite density without significant difference (Table 3 ).

A total of 53 individual $m s p$ alleles were identified (25 for $m s p-1$ and 28 for $m s p-2)$.

For the msp- 1 gene, $14 \mathrm{~K} 1$ type alleles (100-500 bp); 1 RO33-type allele (160 bp) and 10 MAD20 type alleles (100$500 \mathrm{bp}$ ) were identified; for the $m s p-2$ gene 16 different FC27 type alleles $(250-800 \mathrm{bp})$ and 12 3D7 type alleles (350-700 bp) were detected. The analysis of K1 alleles revealed three prevalent alleles $(200 \mathrm{bp}, 250 \mathrm{bp}$, and $400 \mathrm{bp}$ PCR fragments). The RO33 allele did not show any polymorphism, with only one variant $(160 \mathrm{bp})$. The most prevalent
Table 2. Genetic diversity of $P$. falciparum.

\begin{tabular}{lccc}
\hline Family & $N(\%)$ & Family & $N(\%)$ \\
\hline$M S P 1$ & $n=88$ & MSP2 & $N=92$ \\
K1 & $5(5.7)$ & FC27 & $17(18.5)$ \\
MAD20 & $3(3.4)$ & 3D7 & $1(1.1)$ \\
RO33 & $6(6.8)$ & 3D7 + FC27 & $74(80.4)$ \\
K1 + MAD20 & $7(8)$ & Total FC27 & $91(98.9)$ \\
K1 + RO33 & $18(20.5)$ & Total 3D7 & $75(81.5)$ \\
MAD20 + RO33 & $4(4.5)$ & Multiples infection $84(91.3 \%)$ \\
K1 + MAD20 +RO33 & $45(51.1)$ & MOI & 3.9 \\
Total K1 & $75(85.2 \%)$ & & \\
Total RO33 & $73(82.9 \%)$ & & \\
Total MAD20 & $59(67 \%)$ & & \\
Multiples infection & $77(87.5 \%)$ & & \\
MOI & \multicolumn{3}{c}{3.8} \\
\hline
\end{tabular}

Table 3. MOI according age and parasite density.

\begin{tabular}{lccc}
\hline & \multicolumn{3}{c}{ MOI } \\
\cline { 2 - 4 } Age & $m s p-1$ & $m s p-2$ & $m s p-1+m s p-2$ \\
\hline$\leq 5$ years & 3.9 & 3.8 & 4.0 \\
5-10 years & 3.7 & 4.0 & 3.9 \\
$\geq 10$ years & 3.8 & 3.9 & 4.2 \\
$p$ Value & $p>0.05$ & $p>0.05$ & $p>0.05$ \\
Parasite density & & & \\
$\leq 5000$ & 3.6 & 3.4 & 4.2 \\
5001-10 000 & 3.5 & 3.9 & 3.8 \\
$\geq 10000$ & 3.8 & 3.7 & 4.0 \\
$p$ Value & $p>0.05$ & $p>0.05$ & $p>0.05$ \\
\hline
\end{tabular}

Mad20 type alleles were represented by the $\operatorname{Mad} 20_{200}$ and $\operatorname{Mad} 20_{250}$ PCR fragments (Figure 1). For the $m s p-2$ gene, the most prevalent alleles were detected by the $\mathrm{FC} 27_{700}, 3 \mathrm{D} 7_{600}$, and $3 \mathrm{D} 7_{700}$ PCR fragments (Figure 2).

\section{Discussion}

In the Republic of Benin, less attention has been put on the investigation of the genetic diversity of $P$. falciparum than elsewhere. This study is the second after that conducted by Issifou in 2001 [9]. with intensification of malaria control (scale up of use of insecticide-treated bed nets (ITNs), intermittent preventive treatment to pregnant women, early and obligatory parasitological diagnosis before treatment of clinical cases using artemisinin-based combination therapy (ACT)), it was important to characterize new strains of Plasmodium falciparum found in Benin through the importance of mixed infections and the multiplicity of infections. This study was also important for the country because diversity may influence the degree and the expansion of parasite resistance to antimalarial drugs. A high degree of polymorphism is the basis of a large chromosomal recombination thereby increasing the prevalence of the resistance gene. The purpose of this study was to determine the genetic diversity of $P$. falciparum using the two most polymorphic regions of $m s p-1$ and $m s p-2$, in malaria symptomatic subjects in southern Benin. 


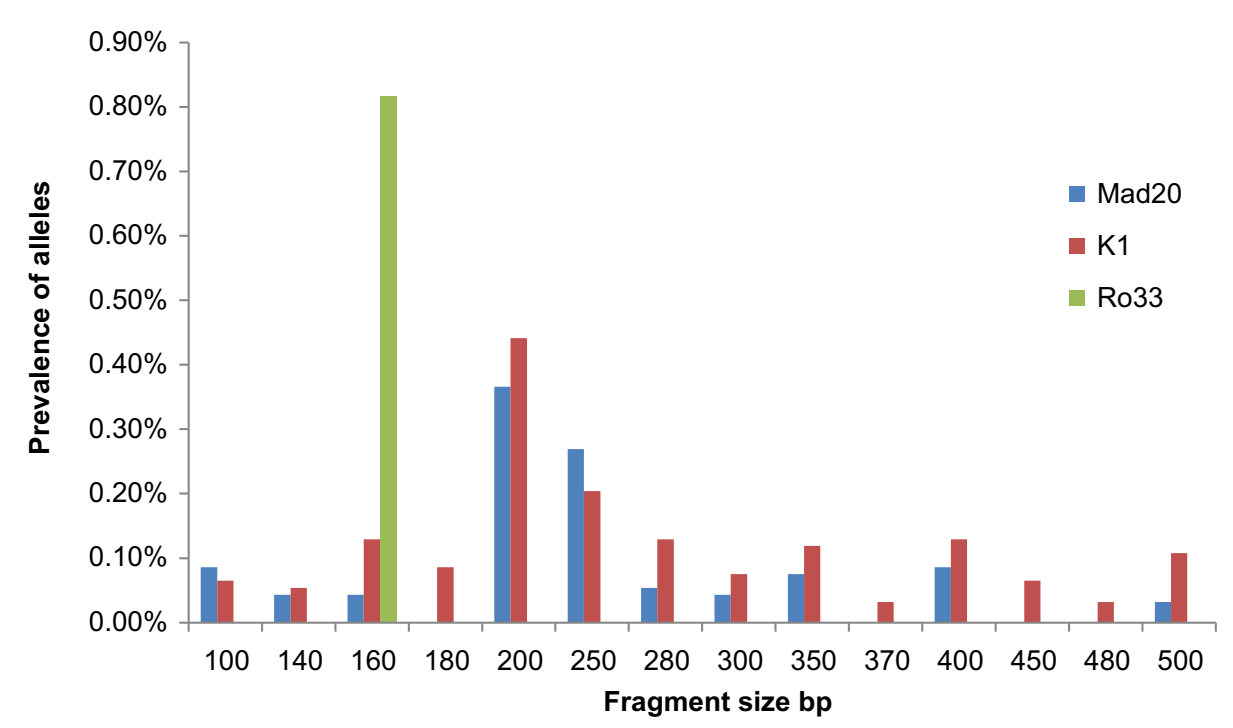

Figure 1. Prevalence of P. falciparum K1, RO33 and MAD20 msp-1 alleles classified by length (in base pairs).

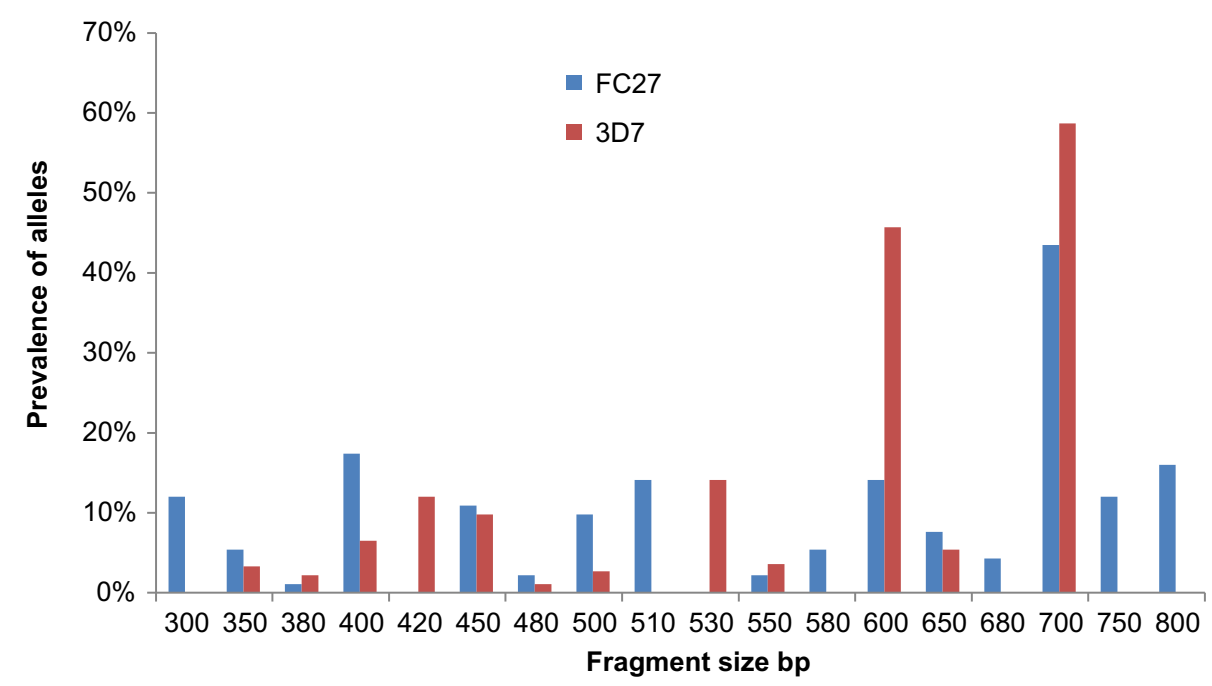

Figure 2. Prevalence of $P$. falciparum $\mathrm{FC} 27$ and 3D7 msp-2 alleles classified by length (in base pairs).

Allele-specific genotyping of $m s p-1$ and $m s p-2$ showed a high genetic diversity in the $P$. falciparum population studied in southern Benin. The degree of polymorphism found in the present study is also consistent with the high level of malaria transmission in the study area as reported previously [22] with a higher diversity of $m s p-2$ in agreement with other studies $[1,21,24]$. Twenty-five alleles of $m s p-1$ were observed, in which, the K1 allelic family was predominant, consistent with most previous studies $[1,9,26]$ but in contrast with one in India [2] showing that the RO33 allele was predominant. The limited polymorphism in the RO33 alleles is similar to the findings of others in African countries [14, 17]. For the msp-2 locus, 28 alleles were found and alleles belonging to FC27 family were most frequently detected. Although this is similar to data reported for a study in Congo [12], it differs from the previous results of Issifou in Benin [9], and Mayengue in Congo Brazzaville [14]. The difference with the results of Issifou may be due to the fact that the study goes far back in the past. Indeed, according to Yuan in Myanmar [29], the majority of alleles showed significant temporal fluctuations through the years. Some genotypes underwent major fluctuations in density, while others were highly stable. It has been shown that parasite polymorphism is poorly evaluated by examination of a single blood sample because genotypes can appear and disappear in a very short time $[4,7]$. This occurred faster in the higher transmission areas when compared to lower transmission areas. In the same context, Mayengue et al. [13] had found evidence of intra and inter-individual variation in the number of parasite genotypes present in the different episodes of malaria. These results suggest the need for several studies on several samples in the same region to assess the genetic profile of parasites. In our study, a limited clonal fluctuation to a maximum of three predominant alleles was found, similar to the results observed in Burkina Faso [26] as well as in other countries of low 
endemicity, and with low polymorphism [3, 8]. The high rate of multiple or mixed $P$. falciparum infections with $m s p-1$ and $m s p-2$ also found elsewhere $[12,26]$ would probably be a consequence of high malaria transmission in the study areas where individuals are exposed to frequent mosquito bites and therefore a significant inoculation of parasite populations that are genetically different. Therefore, these results suggest that the degree of transmission affects the occurrence of mixed infections as initially demonstrated in the Snewin study [24]. Actually, the mean MOI of 3.8 (msp-1) and 3.9 (msp-2) was high compared to those reported in Benin and Congo Brazzaville [9, 14] but consistent with those reported from Gabon, Burkina Faso, and Senegal $[1,26,27]$. This high rate of MOI in the present study suggests that despite the intensification of malaria control interventions involving reduction of malaria infection, the parasite population size and transmission intensity has remained high enough to allow effective genetic recombination of the parasites and continued maintenance of genetic diversity. This echoes the Bogreau study which showed that there is no variation of genetic diversity in a population before and after the use of ITNs.

The fact that the MOI was not influenced by age as shown in other countries $[11,18]$ suggests that the MOI is not directly related to the period of acquisition of immunity in asymptomatic children, but reflects the exposure of subjects to malaria in the endemic area. Thus, a study of the multiplicity of infection and immunity against asexual stages of Plasmodium [12] showed that the samples with the highest multiplicity came from children with significantly lower antibody responses to specific antigens of the asexual parasite. Malaria episodes with many clones would reflect a low level of acquired immunity with consequent limited ability to control the infection. For these authors, the multiplicity of infection with $P$. falciparum could be a potentially useful parameter in the evaluation of interventions against malaria. Several studies have shown a correlation between the MOI and parasite density, but in our study, the MOI did not increase with higher densities similar to results of other studies conducted elsewhere [10, 18].

\section{Conclusion}

These results show a high genetic diversity of populations of $P$. falciparum isolated in southern Benin. This study has demonstrated once again the link between the high level of transmission, mixed infections and multiplicity of infection already found in other countries in the subregion and elsewhere. The MOI is not influenced either by patient age or by parasite density. However, other longitudinal studies to examine the dynamics of the genetic diversity of $P$. falciparum, taking into account other factors such as the degree of transmission, the study of the immune response, and studies of genes conferring resistance to antimalarial drugs, are needed to better target malaria control.

Acknowledgements. We are grateful to the children who participated in the study, as well as to their mothers. We are pleased to thank caregivers from St Luc and Bethesda hospitals, Seme Kpodji health centers, IRD lab workers. The authors declare that they have no competing interests.

\section{References}

1. Aubouy A, Bakary M, Keundjian A, Mbomat B, Makita JR, Migot-Nabias F, Cot M, Le Bras J, Deloron P. 2003. Combination of drug level measurement and parasite genotyping data for an improved assessment of amodiaquine and sulfadoxinepyrimethamine efficacy in treating Plasmodium falciparum malaria in Gabonese children. Antimicrobial Agents and Chemotherapy, 47, 231-237.

2. Bogreau H. 2007. Diversité, multiplicité des infections et résistance aux antipaludiques de Plasmodium falciparum dans un essai contrôlé de moustiquaires imprégnées d'insecticide en zone de forte endémie. www.pasteur.mg/atelier-palu/wp

3. Bharti K, Shukla MM, Sharma YD, Singh N. 2012. Genetic diversity in the block 2 region of the merozoite surface protein-1 of Plasmodium falciparum in central India. Malaria Journal, 11,78 .

4. Druilhe P, Daubersies P, Patarapotikul J, Gentil C, Chene L, Chongsuphajaisiddhi T, Mellouk S, Langsley G. 1998. A primary malarial infection is composed of a very wide range of genetically diverse but elated parasites. Journal of Clinical Investigation, 101, 2008-2016.

5. Ekala MT, Jouin H, Lekoulou F, Issifou S, Mercereau-Puijalon O, Ntoumi F. 2002. Plasmodium falciparum merozoite surface protein 1 (msp-1): genotyping and humoral responses to allelespecific variants. Acta Tropica, 81, 33-46.

6. Genton B, Betuela I, Felger I, Al-Yaman F, Anders RF, Saul A, Rare L, Baisor M, Lorry K, Brown GV, Pye D, Irving DO, Smith TA, Beck HP, Alpers MP. 2002. A recombinant bloodstage malaria vaccine reduces Plasmodium falciparum density and exerts selective pressure on parasite populations in a phase $1-2 b$ trial in Papua New Guinea. Journal of Infectious Disease, $185,820-827$.

7. Guemouri SJ, Boudin C, Fievet N, Ndiaye P, Deloron P. 2006. Plasmodium falciparum genotype population dynamics in asymptomatic children from Senegal. Microbes and Infection, 8, 1663-1670.

8. Heidari A, Keshavarz H, Rokni MB, Jelinek T. 2007. Genetic diversity in merozoite surface protein $m s p-1$ and $m s p-2$ genes of Plasmodium falciparumin a major endemic region of Iran. Korean Journal of Parasitology, 45, 59-63.

9. Issifou S, Djikou S, Sanni A, Lekoulou F, Ntoumi F. 2001. Pas d'influence de la saison de transmission ni de l'âge des patients sur la complexité et la diversité génétique des infections dues a Plasmodium falciparum à Cotonou (Bénin). Bulletin de la Société de Pathologie Exotique, 94, 195-198.

10. Khaminsou N, Kritpetcharat O, Daduang J, Charerntanyarak L, Kritpetcharat P. 2011. Genetic analysis of the merozoite surface protein-1 blocks 2 allelic types in Plasmodium falciparum clinical isolates from Lao PDR. Malaria Journal, 10, 371.

11. Koukouikila-Koussounda F, Malonga V, Mayengue PI, Ndounga M, Vouvoungui CJ, Ntoumi F. 2012. Genetic polymorphism of merozoite surface protein 2 and prevalence of K76T pfcrt mutation in Plasmodium falciparum field isolates from Congolese children with asymptomatic infections. Malaria Journal, 11, 105.

12. Mayengue PI, Ndounga M, Davy MM, Tandou N, Ntoumi F. 2007. In vivo chloroquine resistance and prevalence of the $p f c r t$ codon 76 mutation in Plasmodium falciparum isolates from the republic of Congo. Acta Tropica, 95, 219-225.

13. Mayengue PI, Luty AJ, Rogier C, Baragatti M, Kremsner PG, Ntoumi F. 2009. The multiplicity of Plasmodium falciparum 
infections is associated with acquired immunity to asexual blood stage antigens. Microbes and Infection, 11, 108-111.

14. Mayengue PI, Ndounga M, Malonga FV, Bitemo M, Ntoumi F. 2011. Genetic polymorphism of merozoite surface protein-1 and merozoite surface protein-2 in Plasmodium falciparum isolates from Brazzaville, Republic of Congo. Malaria Journal, 10, 276.

15. Mercereau-Puijalon O. 1996. Revisiting host/parasite interactions: molecular analysis of parasites collected during longitudinal and cross-sectional surveys in humans. Parasite Immunology, 18, 173-180.

16. Miller LH, Roberts T, Shahabuddin M, Mc Cutchan TF. 1993. Analysis of sequence diversity in the Plasmodium falciparum merozoite surface protein-1 ( $m s p-1)$. Molecular and Biochemical Parasitology, 59, 1-14.

17. Mwingira F, Nkwengulila G, Schoepflin S, Sumari D, Beck HP, Snounou G, Felger I, Olliaro P, Mugittu K. 2011. Plasmodium falciparum msp-1, msp-2 and glurp allele frequency and diversity in sub-Saharan Africa. Malaria Journal, 10, 79.

18. Ojurongbe O, Fagbenro-Beyioku AF, Adeyeba OA, Kun JF. 2011. Allelic diversity of merozoite surface protein 2 gene of $P$. falciparum among children in Osogbo, Nigeria. West Indian Medical journal, 60, 19-23.

19. Plowe CV, Djimde A, Bouare M, Doumbo O, Wellems TE. 1995. Pyrimethamine and proguanil resistance-conferring mutations in Plasmodium falciparum dihydrofolate reductase: polymerase chain reaction methods for surveillance in Africa. American Journal of Tropical Medicine and Hygiene, 52, 565568.

20. Programme national de lutte contre le paludisme. Plan stratégique de lutte contre le paludisme au Bénin 2006-2010. http:// www.rbm.who.int/countryaction/nsp/benin.pdf

21. Schoepflin S, Valsangiacomo F, Lin E, Kiniboro B, Mueller I, Felger I. 2009. Comparison of Plasmodium falciparum allelic frequency distribution in different endemic settings by highresolution genotyping. Malaria Journal, 8, 250.

22. Singh N, Shukla MM, Chand G, Bharti PK, Singh MP, Shukla MK, Mehra RK, Sharma RK, Dash AP. 2011. Epidemic of
Plasmodium falciparum malaria in Central India, an area where chloroquine has been replaced by artemisinin-based combination therapy. Transactions of the Royal Society of Tropical Medicine and Hygiene, 105, 133-139.

23. Smythe JA, Peterson MG, Coppel RL, Saul AJ, Kemp DJ, Anders RF. 1990. Structural diversity in the 45-kilodalton merozoite surface antigen of Plasmodium falciparum. Molecular and Biochemical Parasitology, 39, 227-234.

24. Snewin VA, Herrera M, Sanchez G, Scherf A, Langsley G, Herrera S. 1991. Polymorphism of the alleles of the merozoite surface antigens MSA1 and MSA2 in Plasmodium falciparum wild isolates from Colombia. Molecular and Biochemical Parasitology, 49(2), 265-275.

25. Snounou G, Zhu X, Siripoon N, Jarra W, Thaithong S, Brown KN, Viriyakosol S. 1999. Biased distribution of msp1 and msp2 allelic variants in Plasmodium falciparum populations in Thailand. Transactions of the Royal Society of Tropical Medicine and Hygiene, 93, 369-377.

26. Soulama I, Nebie I, Ouedraogo A, Gansane A, Diarra A, Tiono AB, Bougouma EC, Konate AT, Kabre GB, Taylor WRJ, Sirima SB. 2009. Plasmodium falciparum genotypes diversity in symptomatic malaria of children living in an urban and a rural setting in Burkina Faso. Malaria Journal, 8, 135.

27. Vafa M, Troye-Blomberg M, Anchang J, Garcia A, MigotNabias F. 2008. Multiplicity of Plasmodium falciparum infection in asymptomatic children in Senegal: relation to transmission, age and erythrocyte variants. Malaria Journal, 7, 17.

28. WHO. 2000. Communicable diseases cluster: severe falciparum malaria. Transactions of the Royal Society of Tropical Medicine and Hygiene, 94, 0S1-S9.

29. Yuan L, Zhao H, Wu L, Li X, Parker D, Xu S, Zhao Y, Feng G, Wang Y, Yan G, Fan Q, Yang Z, Cui L. 2013. Plasmodium falciparum populations from northeastern Myanmar display high levels of genetic diversity at multiple antigenic loci. Acta Tropica, 125, 53-59.

Cite this article as: Ogouyèmi-Hounto A, Kinde Gazard D, Ndam N, Topanou E, Garba O, Elegbe P, Hountohotegbe T \& Massougbodji A: Genetic polymorphism of merozoite surface protein-1 and merozoite surface protein-2 in Plasmodium falciparum isolates from children in South of Benin. Parasite, 2013, 20, 37.

Reviews, articles and short notes may be submitted. Fields include, but are not limited to: general, medical and veterinary parasitology; morphology, including ultrastructure; parasite systematics, including entomology, acarology, helminthology and protistology, and molecular analyses; molecular biology and biochemistry; immunology of parasitic diseases; host-parasite relationships; ecology and life history of parasites; epidemiology; therapeutics; new diagnostic tools.

All papers in Parasite are published in English. Manuscripts should have a broad interest and must not have been published or submitted elsewhere. No limit is imposed on the length of manuscripts.

Parasite (open-access) continues Parasite (print and online editions, 1994-2012) and Annales de Parasitologie Humaine et Comparée (1923-1993) and is the official journal of the Société Française de Parasitologie. 